\title{
AS PESQUISAS SOBRE ENSINO NAS PRINCIPAIS REVISTAS DE GEOGRAFIA DO BRASIL NOS ÚLTIMOS 10 ANOS
}

Zaira Anislen Moutinho*

Resumo: O objetivo deste paper é discutir e dar visibilidade às principais linhas de pesquisa sobre ensino de geografia no Brasil. Para isso foi feita uma revisão dos artigos sobre ensino de geografia, publicados nos últimos 10 anos nas revistas qualis A de geografia, disponíveis on line. Os artigos foram classificados em seis grupos ou linhas de pesquisa, e foram sintetizadas suas principais conclusões. A partir desse trabalho apontamos algumas questões e sugerimos novos pontos para uma agenda de pesquisa.

Palavras-chave: pesquisa, ensino, revisão, agenda de pesquisa, escola.

\section{RESEARCH ON TEACHING OF GEOGRAPHY IN THE MAIN JOURNALS OF BRAZIL IN THE LAST 10 YEARS}

\begin{abstract}
The aim of this paper is to discuss and give visibility to the main lines of research on teaching geography in Brazil. It was done a review of articles published in the last 10 years in geography magazines qualis A, on line. It was possible to assemble the papers in six groups or lines of research with its main conclusions. Based in these conclusions it is suggested new themes for a research agenda.
\end{abstract}

Keywords: lines of research, teaching, review, school, list of research.

\section{Introdução}

O objetivo deste paper é discutir e dar visibilidade às principais linhas de pesquisa sobre ensino de geografia no Brasil. Para isso foi feita uma revisão dos artigos sobre ensino de geografia, publicados nos últimos 10 anos nas revistas qualis $\mathrm{A}$ de geografia, disponíveis on line. Foi proposto o agrupamento dos artigos nos seguintes eixos temáticos: 1) Formação de professores e saberes docentes; 2) Análise dos livros didáticos e documentos oficiais; 3) Metodologias, abordagens de conteúdos e inovações didáticas; 4) Análise do papel da escola e da geografia escolar; 5) Educação no campo, e 6) Ensino de geografia na educação infantil.

\section{Eixos de pesquisa}

Dentro do eixo formação de professores e saberes docentes, começamos com a discussão de Loch e Fuckner (2005). Os autores analisam a situação do ensino de cartografia em Santa Catarina, a partir da opinião dos professores que lecionam a disciplina no estado. A pesquisa realizada mostra que mais de $70 \%$ dos professores usa - mapa apenas para ilustrar as aulas, enquanto menos de $30 \%$ trabalha confeccionando mapas com os estudantes. Os autores apresentam os principais problemas levantados pelos professores entrevistados em relação à alfabetização cartográfica: incoerências existentes nos livros didáticos; a forma como os mesmos expõem os conteúdos cartográficos e comunicam dados nas representações cartográficas (conteúdos

\footnotetext{
* E-mail: zairaanislen@unb.br.
} 
complexos são expostos em desacordo com o nível de ensino a que se destinam), e o pouco que se aprende, nos cursos de formação de geografia, em relação à conteúdos que possibilitem os professores a desenvolver um programa de ensino/aprendizagem sobre conceitos espaciais e suas representações. Sobre os conteúdos, os autores afirmam que os professores levantaram que os mais difíceis de serem trabalhados são, em escala decrescente, projeções, escalas, coordenadas e simbologia.

Em Gonçalves e Almeida (2006), encontramos a perspectiva do contexto escolar como produtor de conhecimento e por isso os autores usam as categorias de "saber docente" e "conhecimento escolar" para desenvolver seu artigo. Eles criticam as pesquisas que trazem uma concepção de professor apenas como aquele que transfere saberes produzidos por outros, negando aos professores e estudantes as características de subjetividade e de capacidade de instituir sentido, inerentes a todo ser humano. Para esses autores, é necessário considerar os professores como sujeitos do conhecimento e reconhecê-los como pesquisadores. Nessa linha são admitidas três formas de conhecimento no ensino (tópico, operação e situacional) as quais são derivadas do encontro entre a lógica do conteúdo e a lógica da interação. Esses três tipos de conhecimentos são produtos de como os sujeitos se relacionam com o conhecimento. As duas primeiras (tópico e operação) são derivadas das relações de externalidades e a última (situacional) deriva da relação de interiorização.

O número de publicações em 2007 cresce significativamente, com um número da revista Terra Livre dedicado exclusivamente ao tema ensino. Muitos artigos importantes são disponibilizados nesse número. Dentre eles um que aponta para uma triste realidade: "o gigante de pés de barro". O autor do texto (KAERCHER, 2007) fala sobre a geografia escolar e os problemas ligados à sua indefinição, à má formação dos professores e aos obstáculos teóricos, mostrando que ainda impera uma geografia escolar que se baseia em informações de almanaque - uma revista de variedades. Para o autor, muitos dos professores de geografia têm uma epistemologia/teoria da geografia frágil e uma concepção pedagógica que confunde o construtivismo com o laissez faire. O mesmo autor, em outra publicação (KAERCHER, 2008), identifica entre professores as seguintes questões: primeiro, um obstáculo epistemológico, que consiste na crença de que ao se auto intitular como "crítico", ou seja, adepto da Geografia Crítica, pode-se automaticamente, atribuir ao seu trabalho um caráter inovador, alternativo (à Geografia Tradicional) e reflexivo. Segundo, uma prática plena de certezas, identificada em exposições que pretendem explicar o "mundo como ele é" limita o espaço para a descoberta do novo. No mesmo artigo, o autor aponta os seguintes desafios que 0 saber docente deve ser capaz de articular: mostrar ao aluno o desejo de ensinar; construir uma aprendizagem significativa; construir uma efetiva dialogicidade com os alunos; desenvolver o desejo de aprender; buscar a autonomia intelectual embasada numa ética de solidariedade; superar a Geografia da curiosidade, a militância excessiva, a própria omissão e o denuncismo (dogmatismo crítico); e dar sentido às informações, relacionando-as à geografia. 
Somando a essa abordagem, Martins (2009) reflete sobre o papel da formação inicial acadêmica na construção dos saberes docentes. Seria preciso na opinião desse autor, assegurar que a formação de professores possibilite ao profissional docente saber lidar com o processo formativo dos alunos em suas várias dimensões, além da cognitiva, englobando a dimensão afetiva, da educação dos sentidos, da estética, da ética e dos valores emocionais. Para o autor a qualidade do ensino está intensamente ligada à qualidade da formação do profissional.

O artigo de Katuta (2007) dá uma grande contribuição às discussões sobre a formação de professores e parece responder ao artigo de Kaercher. Para a autora, não se trata de afirmar que os docentes são mal formados ou despreparados para a realização do trabalho em sala de aula. Para ela, é necessário compreender que as mudanças possibilitadas pelo desenvolvimento do "meio técnico científico e informacional", alteraram de tal forma a realidade objetiva, e em curto espaço de tempo, que as práticas pedagógicas e as linguagens, tradicionalmente empregadas no ensino formal da geografia, acabaram por se tornar ainda mais limitadoras da possibilidade de entendimento das espacialidades engendradas. Em Katuta, trata-se de assumir o inacabamento humano e, consequentemente, do educador, entendendo que é nessa perspectiva que se podem constituir práticas pedagógicas em geografia que objetivem a apreensão, (re)apresentação e compreensão de um espaço entendido como coabitação tensa da diferença e da unidade. Para a autora só é possível fazer isso por meio da apropriação das mais diversas linguagens que apresentam o espaço em sua identidade e diferença, em sua homogeneidade e heterogeneidade. Somando-se às questões que são colocadas aos professores na atualidade, V. Silva (2007a; 2007b) faz uma análise da situação da formação do professor de geografia diante das novas demandas da sociedade informacional, onde o conteúdo da tecnologia, inclusive, passou a se constituir num dos eixos norteadores das áreas de conhecimento da educação básica. Silva mostra que, na atualidade, é desejoso que o professor domine as tecnologias ligadas às produções geográficas, para ensiná-las em uma escola que procura formar habilidades e competências mais do que propor o domínio de conteúdos. Porém, o mesmo autor, em artigo publicado em 2011, pontua que as ferramentas tecnológicas apenas potencializam as possibilidades de aprendizagem, mas não as garantem sozinhas. É preciso, além disso, dominar os conceitos e categorias da disciplina. Para ultrapassar uma "geografia em migalhas", oferecida cotidianamente através da tecnologia, especialmente da comunicação, é preciso dominar os conceitos e categorias da disciplina. As tecnologias e as tecnologias informacionais sozinhas não possibilitam a formação do raciocínio espacial que, para o autor, passa pela apropriação teórica da disciplina.

$\mathrm{Na}$ linha da apropriação de diversas linguagens, Silva e Ramires (2008) defendem a necessidade de bacharelado e licenciatura caminharem juntos. Para eles os currículos devem ser carregados da diversidade de leituras geográficas e identificá-las tempo-espacialmente em seu desenho político-pedagógico. Para Silva e Spinelli (2007), formar profissionais críticos e reflexivos pressupõe que essa formação seja, antes de mais nada, o desenvolvimento da 
competência investigativa. A pesquisa, para eles, é ela própria um desafio e representa concretamente a possibilidade de descoberta de nossa condição no mundo, como um exercício livre, criativo e consciente em busca de respostas ao inquietante momento que se vive, no terreno dinâmico do acontecer, das criações e das transformações que conformam o mundo atual. Os autores apresentam a experiência da Universidade de Passo Fundo que está construindo seu curso de licenciatura em geografia com foco na pesquisa.

Dentro do eixo formação de professores e saberes docentes, é possível inferir que as pesquisas consideram 0 professor, por um lado, deficiente, por ter tido uma formação frágil e carregar vícios epistemológicos, ou por não adotar o foco preciso, no caso a pesquisa, como forma de ensinar. Por outro lado, os saberes docentes são considerados incompletos, porque a prática docente está inserida em um contexto de mudanças velozes, que em geral é, no mínimo, difícil de acompanhar. É possível questionar o seguinte: para além da frágil formação inicial do professor e das dificuldades impostas pela velocidade do mundo contemporâneo, quais outros fatores interferem na prática cotidiana do professor? Quem é esse professor de que as pesquisas tratam? Como sua subjetividade, seus desejos e incertezas estão inseridos na sala de aula? Como esse professor é visto na comunidade em que atua? Como é sentido pelos educandos? Com qual grau de respeito, seriedade e importância seu trabalho é produzido ou é percebido pela comunidade? Será que o professor se encontra num contexto de desvalorização social tão forte que é incapaz de perceber ou mobilizar suas próprias potencialidades? O cotidiano do professor, de geografia em especial, precisa ser estudado considerando toda a complexidade presente na sala de aula, aqui incluindo a própria percepção dos estudantes em relação à disciplina. Não cabe aqui negar a deficiência da formação do professor, mas chamar a atenção para os exemplos de sucesso em sala de aula e as inovações que os professores implementam no cotidiano escolar. É preciso ainda destacar que a utilização e domínio das novas tecnologias no ensino, passam pela necessária estruturação tecnológica das escolas públicas, em especial nas periferias. Afinal, como afirmou Milton Santos (2002), a tecnologia é a face da esperança que compõe a globalização.

O tema abordado no eixo papel da escola e da geografia escolar tem recebido bastante ênfase dos pesquisadores, dentre eles importantes nomes como Sposito, Castellar, Cavalcanti e Callai. Para Sposito (2002), as possibilidades e limites de construção de uma sociedade mais justa e humana passam, por um lado, pelo desvendamento das formas como se relacionam o espaço e o tempo, na atualidade, e, por outro, pelo reconhecimento claro dos impasses e conflitos que marcam nossa sociedade, daí a importância da geografia escolar. A escola nessa perspectiva é o locus da formação crítica. No entanto, Smith (2003) alerta para o fato de que a educação não vai cumprir esse papel se transformada em uma "fábrica de salsichas". A educação como um setor industrial distinto está em processo de ser totalmente engolida pelo capital financeiro e especulativo. Cardoso (2007), ao analisar o papel da escola, identifica em seu estudo, sobre o processo de modernização da cidade de Paraíba do Norte, que a própria localização da escola se modifica de acordo com os 
interesses sociais. Uma perspectiva inovadora sobre o papel da geografia está contida no artigo de Refatti e Rego (2003) que estabelece relações conceituais e operacionais entre representações de mundo, manejo simbólico e aproximações entre clínica psicopedagógica e ensino de geografia. Esses autores levam a geografia escolar para uma dimensão interessante, onde o ensino, especificamente no caso estudado, pode ter uma função terapêutica, assim como a terapia tem uma dimensão de ensino. Para eles, não é porque o manejo do espaço geográfico possa ser um instrumento usado para subjugar, que não se possa conceber as potencialidades do manejo em sentido contrário, como um instrumento utilizado na direção da emancipação coletiva da "aventura humana sobre a face do planeta". O ensino de geografia atua terapeuticamente na medida em que pode exercitar a representação de mundo, isto é, torná-la mais elaborada, mais consciente, qualificando a própria relação do sujeito da representação, com o seu mundo. O ensino de geografia pode ser o processo pelo qual o paciente e/ou aluno compreenda o que está em torno como algo que também está dentro de si, internalizado, algo que o constitui como sujeito. Apesar da potencialidade identificada por Refatti e Rego (2003), Gaúdio (2007) mostra que, na realidade, o ensino de geografia se mobilizou durante muitos anos em torno da construção da identidade nacional, ou seja, potencializando a partir da referência à natureza e extensão territorial brasileiras, "nosso povo pacífico e ordeiro" e à partir da utilização intensiva do termo país, termo híbrido cujo sentido é construído, para esse último autor, na e a partir da escola básica, e que permanece bastante impreciso no campo das Ciências Humanas.
Defendendo a perspectiva de que uma das funções sociais da escola é a formação para a cidadania, Teodoro (2009) destaca a importância do "estudo do lugar", como ferramenta de construção da cidadania, junto a jovens em situação de risco social. O autor afirma que o ensino de geografia deve promover o conhecimento integral da realidade através do aguçamento da percepção crítica da realidade e da compreensão da Geografia desses sujeitos: qual seu lugar de origem, por que se localizam em determinados espaços, qual a percepção que possuem sobre sua dinâmica espacial e quais formas de territorialização que utilizam. A partir desse conhecimento, os sujeitos poderão levantar hipóteses sobre o desafio de sua realidade e procurar soluções.

Na mesma direção, Callai, Cavalcanti e Castellar (2009) apresentam artigo com enfoque na temática da "cidade educadora". Para elas, a escola apresenta uma grande capacidade para enfrentar o desafio de compreender o lugar, tanto do ponto de vista da produção e organização espacial, quanto das mobilizações dos grupos sociais. A interpretação dos fenômenos geográficos ganha significado quando o aluno entende a diversidade da maneira como se dá a organização dos lugares, quando compreende o conceito de território. Por isso, as autoras reafirmam que a leitura de mapas e a elaboração dos mapas cognitivos são imprescindíveis para a compreensão do espaço. No artigo, apresentam o projeto da "cidade educadora" como aquele que objetiva a formação de cidadãos que conheçam, de fato, a cidade em que vivem, que compreendam os lugares como locais produzidos segundo projetos sociais e políticos determinados e que, sendo assim, sua participação nessa produção é viável, 
desejável e pode contribuir para que seja garantida nela a melhor vida coletiva possível. Cavalcanti (2011) reforça o tema, afirmando que o papel social da geografia escolar, é ajudar a construir uma compreensão significativa da realidade, compreensão, por sua vez, necessária para o questionamento e para atuação mais autônoma nessa realidade. Esse conhecimento deve ter como referência o lugar do aluno, e trabalhar com essa escala de análise como referência para compreender escalas mais amplas, mas, como destaca Cavalcanti, na geografia não se admite mais excluir as diferentes compreensões, explicações e determinações da configuração do real, sejam elas simbólicas, econômicas ou naturais.

Fica evidente, com 0 exposto anteriormente que, para os autores que discutem essa temática, o papel da geografia escolar e do ensino relaciona-se ao aumento da capacidade dos sujeitos de atuar em sua realidade a partir da compreensão da organização do espaço, partindo do lugar, em busca de entendimentos dialéticos lugar/totalidade. Uma questão, entretanto, salta aos olhos: será que a compreensão da organização do espaço leva linearmente à construção de uma postura mais ativa e de mobilização em relação à organização do espaço? Qual o papel das metodologias no processo de construção desse conhecimento? Quais são os fatores que levam os sujeitos a estarem mobilizados e atuarem de forma cidadã, e qual o grau de influência do conhecimento?

O eixo livro didáticos e documentos oficiais pode ser subdividido em dois subeixos. O primeiro deles inclui os autores que analisam o conteúdo dos livros didáticos, começando por Kunzler (2007), que analisa a influência do período militar na geografia, especificamente nos livros didáticos. 0 discurso essencialmente descritivo da disciplina encontra, segundo o autor, as suas raízes na geografia militar, em que se faz o inventário dos dados úteis. As obras analisadas, relata o autor, chamam a atenção pela linguagem adotada, basicamente formada por frases curtas e de sentido positivo, geralmente de exaltação do país em todos os seus aspectos, com raras inferências sobre os assuntos negativos, que são apresentados como já superados ou em vias de superação graças à ação do governo. A conclusão de Kunzler é de que os livros didáticos serviam como folhetins propagandísticos do governo e ocultavam muitos aspectos importantes.

Tonini (2008) realizou uma leitura sobre o significado de ser um país "desenvolvido" ou "subdesenvolvido", nas imagens inscritas nos livros didáticos de geografia do ensino fundamental. Nesse texto o autor identifica as imagens que criam esses territórios (subdesenvolvidos e desenvolvidos).

Macário (2011) enfatiza que a distância entre as práticas de ensino e os textos dos livros didáticos torna esse recurso um dos maiores desafios às práticas comprometidas com os saberes locais e sua inclusão nos currículos escolares. Isso porque, para o autor, o uso desse recurso repousa sobre práticas de ensino ainda vigentes nas escolas brasileiras, que reproduzem a utilização estereotipada do livro didático e de sua vinculação a modelos de conhecimento, tornando a geografia um conhecimento de uma única corrente ou concepção geográfica e, consequentemente, 
desrespeitando a diversidade de propostas e abordagens. A utilização do livro didático em geral, para o autor, deixa de lado aspectos importantes, como 0 de considerar a caracterização e descrição do espaço vivido e sentido pelos diferentes sujeitos pela representação, a partir do uso das práticas cartográficas e das técnicas de tratamento computacional das informações geográficas obtidas (geoprocessamento e SIG). Albuquerque (2008) coloca em destaque a complexa relação entre legislação que regula o ensino, produção de livros didáticos e o papel do autor. Para isso o autor faz um estudo de caso da produção de livros em Pernambuco no final do século XIX, no contexto de reformulação da legislação.

Desse eixo, é importante destacar que os autores estão colocando em relevo o papel político do conteúdo dos livros didáticos e o problema da incorporação do estudo do lugar como ponto de partida para a produção do conhecimento na sala quando se usa de forma equivocada o livro didático.

No segundo sub-eixo, que engloba a análise de documentos oficiais, Rego da Rocha (2009) analisa as reflexões e proposições apresentadas por Ruy Barbosa (no final do século XIX) e Delgado de Carvalho (primeiras décadas do século $X X$ ) acerca da necessidade de renovação do ensino da geografia praticado nas escolas brasileiras. Nessas reflexões o autor identifica a defesa de um ensino de geografia assentado nos princípios científicos que estavam presentes naquele momento histórico, e que propunham a introdução, nas salas de aula, de uma geografia moderna, que deveria ser ensinada através de uma pedagogia moderna.
Em Kimura (2009), encontramos um relato da história da criação e evolução curricular da disciplina de geografia no estado de São Paulo. Analisando o mesmo objeto, Pereira (2011) conclui que o recente processo de construção e implementação do currículo no estado de São Paulo foi falho, pois desconsiderou o cotidiano escolar na medida em que uniformizou os conteúdos e práticas, retirando a autonomia do professor e colocando sobre este o ônus dos baixos indicadores. Ressalta a necessidade de pesquisas focadas no cotidiano escolar, na sala de aula, no empírico. Nas palavras da autora, ainda que não explícito, o currículo parte da concepção de que o problema atual é o professor que, incapaz de resolver problemas que resultam em baixos índices de avaliação, deve ser direcionado passo a passo para realizar as atividades de sala de aula, entendendo essa de modo generalizado, como se todas as classes e escolas tivessem as mesmas realidades e problemas. Essa análise também chama a atenção para a história da geografia escolar e para a produção dos currículos, acentuando a necessidade de se lembrar e contar aspectos de uma trajetória que integra seu processo constituinte.

A produção de R. Santos (2010) é uma contribuição para pesquisadores interessados nos efeitos da lei 10.639/03, que torna obrigatório o ensino da "História e Cultura Afro-Brasileira". O autor infere que a adoção da temática pode revitalizar o ensino de geografia, apontando alguns novos conceitos sobre a presença negra no território brasileiro e identifica que a geografia pode ainda contribuir, apontando a dimensão espacial do conceito de raça. Já Albuquerque (2008) relata a forma isolada e centralizada com que os Parâmetros Curriculares 
Nacionais (PCN) da área de geografia e história foram criados e impostos, na década de 1990. Além disso o autor aponta para a importância de contextualizar as metodologias, indicando, por exemplo, que não há incompatibilidade entre o credo neoliberal e aqueles defendidos pela

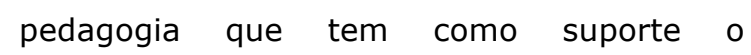
construtivismo.

Nesse sub-eixo, as análises ficaram mais focadas nos currículos oficiais do estado de São Paulo e sua forma de implementação. Talvez um estudo comparativo entre estados possibilite algumas generalizações e apontamentos em relação ao currículo da disciplina e ao entendimento dos estudos geográficos.

O eixo metodologias, abordagens de conteúdos e inovações didáticas merece ser iniciado pelo trabalho de Eerola (2004), que traz o relato de uma experiência didático-pedagógica baseada no método investigativo intitulado psicogeografia, usando a geoestética como recurso didático para o ensino de geociências. Nessa perspectiva, o espaço geográfico é entendido como sujeito, que influencia a sociedade e os sujeitos. Correia (2009), também trazendo inovações, busca refletir as mudanças socioculturais e científicas e as adaptações que a geografia fenomenológica, seu método e seu caráter pedagógico podem oferecer ao desenvolvimento humano. Esse texto traz para o centro o trabalho metodológico com as representações espaciais de cada educando, dessa maneira tornando as representações, fundamento das ações.

Hasseler (2009) defende os estudos focados no lugar como meio adequado de "alfabetizar" em geografia. Para esse autor o estudo do lugar é o método para se pensar na possibilidade de um ensino contextualizado. Deve-se assim, mostrar que este espaço está impregnado de sua ação, que se faz geografia no dia a dia, através do trabalho que é a constante na relação sociedade - natureza. Então a partir daí se terá mais chances de realizar um diálogo entre professores e alunos. Para o estudo do lugar e da geografia, Richter, Marin e Decanini (2010) defendem o uso dos mapas metais, os quais possibilitam evidenciar a representação que os estudantes fazem de seu lugar, possibilitando a aprendizagem e o aparecimento de contradições. Nas palavras dos autores "no momento em que o aluno construir, em sala de aula, o mapa de sua cidade, tendo a colaboração dos saberes científicos ensinados na escola, esse indivíduo fará uma revisão do espaço representado e poderá incorporar leituras individuais, coletivas e, quiçá, questionadoras" (RICHTER; MARIN; DECANINI, 2010, p. 92).

Indo em outra direção, para o trabalho com mapas em sala de aula, Panizza (2011) apresenta roteiro para trabalhar com imagens de satélites no ensino de geografia. Ilustra as seguintes perguntas como pontos de partida e trabalho sobre as imagens: Quais seriam os elementos explicativos para a localização das estruturas espaciais identificadas? Qual legenda representa as estruturas espaciais identificadas? Quais seriam os mecanismos explicativos de tais estruturas espaciais?

É importante aqui fazer uma ressalva, a de que o uso de mapas mentais e a produção de mapas formais são duas abordagens que, a nosso ver, são fundamentais dentro da sala de aula. Isso porque, como já demonstraram os autores 
que publicaram sobre os temas, cada uma dessas abordagens tem funções no contexto do educando e servem para seu desenvolvimento intelectual, pois, enquanto os mapas mentais possibilitam maior conhecimento e interpretação de sua realidade e a expressão da representação espacial do sujeito, os mapas formais empoderam os educandos a lidar com ferramentas tecnológicas de indiscutível importância no mundo contemporâneo.

Guimarães (2007) analisa as relações entre o ensino de geografia e a mídia no atual mundo globalizado. Porém, para a autora, a geografia, na mídia, torna-se espetáculo e é enciclopédica. Ela enfatiza a necessidade de se aproveitar dos conhecimentos geográficos disponibilizados nas mídias, mas sempre contextualizando a produção de sentido do material. O professor deve auxiliar os estudantes a analisar o discurso geográfico na mídia. Já em Oliveira (2008) existe uma "geografia mundana", caracterizada por uma quase indisciplina na atividade de construção e difusão dos conhecimentos espaciais, "que não entende o plano de ensino, a hora-aula e a repartição estrutural das responsabilidades disciplinares como os elementos mais definidores do ensino de qualidade". Nesse contexto a escola é um locus de rigidez e tradicionalismo científico que deve ceder para a nova produção, com base na cultura da mídia. As ciências da comunicação podem e devem servir como as principais interlocutoras para a transformação. Albuquerque e Medeiros 2012) enfocam a importância do trabalho com inclusão digital e apresentam a experiência do SIG-WEB Ceará em Mapas Interativos, como uma ferramenta de significativa importância para o ensino. Com enfoque nas competências e habilidades a serem desenvolvidas na disciplina de geografia, expressam entre elas a representação e comunicação, especificamente enfatizando ler, analisar e interpretar os códigos específicos da Geografia (mapa, gráficos, tabelas etc.). Ainda no eixo de metodologias, Campos (2008) relata o trabalho sobre o período da ditadura militar a partir da análise de letras de músicas. O autor reforça a importância da utilização de diferentes ferramentas pedagógicas no contexto da sala de aula. Couto (2010) apresenta alguns passos com o objetivo de auxiliar a reflexão dos professores em relação a sua prática em sala de aula. Nas palavras da :

1० passo: o conhecimento da prática social, práticas/saberes espaciais do universo cultural e do contexto socioespacial dos alunos. $2^{\circ}$ passo: a problematização das práticas/saberes espaciais; transformação em problemas significativos do ponto de vista de quem aprende - oriundos de sua prática social -, mas também do ponto de vista dos processos espaciais/sociais-naturais do mundo globalizado. $\quad 3^{\circ}$ passo: a instrumentalização, isto é, a construção e apropriação de instrumentos teóricos e práticos, de ferramentas culturais e científicas, indispensáveis ao equacionamento dos problemas levantados das práticas e saberes espaciais. $4^{\circ}$ passo: a catarse, isto é, a síntese superior a partir dos saberes sincréticos, sua transformação em sínteses de muitas determinações da realidade concreta. $5^{\circ}$ passo: a prática socioespacial, como ponto de chegada da unidade teoria e prática, sua compreensão mais consciente e sua possibilidade de transformação por partes dos alunos (COUTO, 2010, p. 120).

Assim, para Couto, a aula segue as duas direções simultaneamente. O movimento que vai das práticas e saberes espaciais à construção dos conceitos geográficos exige o caminho inverso, aquele 
em que a teoria social do espaço permite compreender melhor e transformar a prática e reconstruir os saberes.

\section{O eixo o ensino de geografia nas} séries iniciais conta com três artigos: Straforini (2002), Braga (2007) e Sales e Andrade (2007). O primeiro discute a possibilidade do entendimento do espaço geográfico como totalidade-mundo, no contexto das séries iniciais. Para esse autor, o ponto de partida deve ser sempre o imediato concreto ou o lugar, mas esse entendido como o ponto de encontro de lógicas locais e globais, próximas e longínquas, uma vez que no atual período de globalização as escalas não se apresentam dispostas linear e independentemente. O segundo autor citado, analisa as possibilidades dos professores desse nível de ensino para desenvolverem uma Geografia Crítica considerando suas formações para o trabalho com essa disciplina. Nesse texto o autor identifica a distância entre as políticas expressas nos documentos oficiais e a prática cotidiano dos professores. Isso porque concepção dos PCN é bastante eclética, dando margem para o ensino do espaço geográfico tanto numa perspectiva da geografia crítica quanto da geografia humanística. Porém, como ressalta o Braga, se alguma dessas concepções está ou não sendo perseguida, como isso está sendo feito, até onde esse processo já caminhou, são questionamentos que ainda estão postos. Para os autores é necessário que seja desenvolvido, ainda nas primeiras séries, um processo de alfabetização de forma integral, buscando realizar a possibilidade e o desejo de ler o mundo.

Esse eixo chama a atenção para a peculiaridade do ensino de geografia nas séries iniciais. A começar pela formação do professor e a possibilidade dos educandos de compreender determinados conceitos como os de totalidade mundo.

O eixo educação no campo conta com a publicação de Alexandra M. Oliveira (2011) nesse artigo a autora aponta que 0 paradigma da questão agrária trouxe influências teóricas e práticas para se estudar o movimento desigual, contraditório e combinado do território brasileiro e suas transformações recentes. Tomando o território como um conceito central infere a importância da educação, entendida como espaço de formação, para o desenvolvimento rural e o avanço da reforma agrária. Para a autora, que se baseia em Freire (2006), a educação é entendida como um ato de intervenção intencional no qual o sujeito, consciente de sua ação, deve agir com o seu conhecimento no sentido da transformação. É exatamente esse entendimento de educação que vai diferenciar "educação do campo" de "educação rural". O papel educativo geografia nesse contexto, para a autora, é de promover a compreensão dos processos de espacialização e territorialização da luta pela terra. E o desafio, para ela, estaria no fato de que estudar saberes e práticas pedagógicas do campo coloca o professor de geografia diante do problema de dar sentido às palavras a partir do conhecimento específico e das experiências individuais e coletivas construídas na realidade do campo. A autora critica a inexistência de políticas que pensem a formação de docentes específicas para trabalhar com educação do campo e afirma que a desarticulação das escolas rurais faz parte de uma estratégia de desestruturação dos movimentos sociais do campo. 
Em relação à educação do campo, é possível constatar a inexpressivo número de artigos sobre o tema nas revistas de grande impacto. Dessa maneira o tema parece ainda uma grande floresta a ser conhecida, principalmente quando se vê a expansão dos cursos de licenciatura para educação no campo. Qual a dimensão (conteúdos, metodologias, currículo oculto) da geografia escolar nos assentamentos e nas escolas família agrícola? Quais o resultado são esperados e podem ser observados dessa formação específica em educação no campo?

\section{Conclusões}

Estas conclusões buscam retomar alguns questionamentos já colocados por outros autores e levantar novos, no intuito de contribuir com reflexões sobre uma possível agenda de pesquisa sobre ensino de geografia.

Inicialmente, é preciso destacar que a produção científica sobre ensino nas revistas de referência da área é escassa, se considerar que somam um pouco mais de 50 artigos nos últimos 10 anos. Esses números por si só revelam o pequeno espaço dedicado a essa temática nas principais revistas de geografia no Brasil. Algumas linhas de pesquisa contam com apenas uma publicação on line qualis A. Isso pode ser fruto de uma agenda de pesquisa ainda pouco explorada ou um descaso por parte do corpo editorial das revista qualis A.

Sabemos que ao contrário da maioria das disciplinas, que nasceram primeiro na academia e depois se tornaram escolares, a geografia foi primeiro escolar. Isso foi responsável, em grande parte, não só pela legitimação da nova ciência geográfica, como também pela sua institucionalização (REGO DA ROCHA, 2009). Será que esse pouco espaço dado a temática do ensino de geografia revela um certo desprezo por sua própria origem, como um migrante que tem vergonha de valorizar sua origem por sofrer preconceitos?

Outras questões para uma agenda foram levantadas por Cavalcanti (2011). Dentre elas as questões referentes à formação de conceitos no ensino de Geografia, que para a autora deve ser compreendida em sua complexidade e no seu papel para o desenvolvimento do pensamento teórico. Outras questões são aquelas ligadas às investigações que focam as metodologias de ensino, com o propósito de formular propostas mais eficazes para o ensino. Kaercher (2007) também aponta um elemento para uma agenda de pesquisa.

$$
\text { Para o autor, é imprescindível }
$$
responder à seguinte questão "qual o sentido da geografia no currículo? Ou qual a especificidade da geografia como disciplina formal? Nessa mesma ordem parece necessário a realização de pesquisas com foco nos educandos e no desenvolvimento alcançado por esses através da geografia. E, por fim, pesquisas que revelem o valor que a sociedade, as comunidades e educandos dão a geografia como disciplina e em qual contexto se insere essas posições. A busca por essas resposta e uma agenda de pesquisa que consiga dar visibilidade a seus resultados pode permitir que tenhamos mais sustentação para falar do ensino de Geografia que se pratica e de suas implicações socioeducacionais. Afinal, a Geografia deve muito à geografia escolar, e permitir que ela perca espaço pode ser um tiro no próprio pé. 


\section{Referências bibliográficas}

ALBUQUERQUE, E.; MEDEIROS, C.; GOMES, D.; CRUZ, M. Sig-web ceará em mapas interativos, novas ferramentas na cartografia escolar. Revista Mercator, América do Norte, v. 11, n. 24, 2012.

ALBUQUERQUE, M. A autoria de livro didático de geografia em Pernambuco no século xix: uma relação entre a legislação e a elaboração. Terra Livre, Dourados/MS, ano 24, v. 2, n. 31, p. 163-171, jul./dez. 2008.

. Currículos de geografia: da abertura política aos PCNs. Revista Mercator América do Norte, v. 4, n. 5, 2005.

BARROS, O. N. F. et al. Disparidades educacionais de Londrina-PR: o que os mapas nos revelam? Geosul, Florianópolis, v. 23, n. 46, p. 197218, jul./dez. 2008. Disponível em: <http://www.periodicos.ufsc.br>. Acesso em: 20 maio 2012.

BRAGA, M. C. B. O ensino de geografia nas séries iniciais do ensino fundamental: uma análise dos descompassos entre a formação docente e as orientações das políticas públicas. Terra Livre, Presidente Prudente, ano 23, v. 1, n. 28, p. 129-148, jan./jun. 2007.

CAMPOS, R. R. Ditadura militar, geografia e MPB: uma proposta voltada ao ensino. GEOSUL, Florianópolis, v. 23, n. 45, 2008. Disponível em: <http://www.periodicos.ufsc.br/index .php/geosul/article/view/12599/1176 7>. Acesso em: 17 maio 2012.

CALLAI, H. C.; CAVALCANTI, L. S; CASTELLAR, S. M. V. Lugar e cultura urbana: um estudo comparativo de saberes docentes no brasil. Terra Livre, Presidente Prudente, ano 23, v. 1, n. 28, p. 91-108, jan./jun. 2007.

CARDOSO, C. A. A. O lugar da escola na cidade: a escola normal da Parahyba no início do século XX. Terra Livre, Presidente Prudente, ano 23, v. 1, n. 28, p. 109-128, jan./jun. 2007.

CAVALCANTI, L. S. Ensinar geografia para a autonomia do pensamento (Teaching Geography in Order to Achieve
Autonomy of Thought). Revista da Anpege, América do Norte, v. 7, n. $1,2011$.

CORREIA, M. A. Possibilidades epistemológicas e pedagógicas da geografia humana em seu tronco humanístico cultural. Terra Livre, Presidente Prudente, ano 23, v. 2, n. 29, p. 143-162, ago./dez. 2007.

COUTO, M. A. C. Ensinar a geografia ou ensinar com a geografia? Das práticas e dos saberes espaciais à construção do conhecimento geográfico na escola. Terra Livre, São Paulo, ano 26 , v. 1 , n. 34 , p. 109-124, jan./jun. 2010.

EEROLA, T. T. A psicogeografia no ensino de geociências no espaço construído: experiências nos shopping centers da Grande Florianópolis. Geosul, Florianópolis, v. 19 , n. 37, p. 135156, jan./jun. 2004. Disponível em: <http://www.periodicos.ufsc.br>. Acesso em: 17 maio 2012.

FONSECA, V. M.; BRAGA, S. R.; CICILLINI, g. A educação ambiental como possibilidade de unificar saberes. Terra Livre, v. 28 , n. 1 , p. 239-256, 2007.

GÁUDIO, R. S.; BRAGA, R. B. A geografia, a educação e a construção da ideologia nacional. Terra Livre, Presidente Prudente, ano 23, v. 1, n. 28, p. 177196, jan./jun. 2007.

GIROTTO, E. Escola, lugar e poder: uma análise geográfica a partir de São Caetano do Sul, SP, Brasil. GEOUSP - Espaço e Tempo, América do Norte, n. 1, dez. 2011. Disponível em:

<http://citrus.uspnet.usp.br/geousp/ ojs2.2.4/index.php/geousp/article/vie w/452/264>. Acesso em: 15 maio 2012.

GOLÇALVES, A. R. Professores e conhecimentos escolares: perspectivas teórico-metodológicas de investigação em didática da geografia. Geosul, Florianópolis, v. 21, n. 42, p. 93-112, jul./dez. 2006. Disponível em: 
<http://www.periodicos.ufsc.br>. Acesso em: 20 maio 2012.

GonÇALVES, A. R.; ALMEIDA, R. D. O "lugar" não é mais o mesmo: articulação dos múltiploslos espaços-tempos cotidianos nas práticas escolares. Terra Livre, Presidente Prudente, ano 23 , v. 2, n. 29, p. 231-246, ago./dez. 2007.

GUIMARÃES, I. Ensino de geografia, mídia e produção de sentidos. Terra Livre, Presidente Prudente, ano 23, v. 1, n. 28, p. 45-66, jan./jun. 2007.

HASSLER, M. Contribuição geográfica para o estudo do lugar (A geographical contribution for the study of the place). Revista Mercator, América do Norte, v. 8, n. 15, 2009.

KAERCHER, N. Gigante de pés de barro comendo pastel de vento num fast food? Terra Livre, Presidente Prudente, ano 23, v. 1, n. 28, p. 2744, jan./jun. 2007.

Quando a geografia crítica pode ser um pastel de vento (When critical geography can be ineffectual). Revista Mercator, América do Norte, v. 3, n. 6, 2004.

KATUTA, A. M. A educação docente: (re)pensando as suas práticas e linguagens. Terra Livre, Presidente Prudente, ano 23 , v. 1 , n. 28, p. 221238, jan./jun. 2007.

KIMURA, S. Linguagem e produção de sentidos no ensino de geografia. Terra Livre, São Paulo, ano 26, v. 1, n. 34, p. 177-188, jan./jun. 2010.

- Território de luzes e sombras: a proposta de ensino de geografia da Cenp. Terra Livre, São Paulo, ano 25 , v. 1, n. 32, p. 17-30, jan./jun. 2009.

KUNZLER, E. C.; WIZNIEWSKY, C. R. F. A ideologia nos livros didáticos de geografia durante o regime militar no Brasil. Terra Livre, Presidente Prudente, ano 23, v. 1 , n. 28 , p. $197-$ 220, jan./jun. 2007.

LOCH, R. E. N.; FUCKNER, M. A. Panorama do ensino de cartografia em Santa Catarina: os saberes e as dificuldades dos professores de geografia. Geosul, Florianópolis, v. 20, n. 40, p
105-128, jul./dez. 2005. Disponível em:

<http://www.periodicos.ufsc.br>. Acesso em: 17 maio 2012.

MACÁRIO, M. Imagem do livro didático e planejamento do ensino em geografia: desafios a formação de conceitos espaciais. GEOgraphia, América do Norte, n. 12, nov. 2011. Disponível em:

<http://www.uff.br/geographia/ojs/in dex.php/geographia/article/view/385/ 304>. Acesso em: 21 maio 2012.

MARTINS, R. Construção dos saberes docentes do professor de geografia (The construction of knowledge of teachers teacher of geography). Revista Mercator, América do Norte, v. 8, n. 16, 2009.

OLIVEIRA, A. Campesinato, ensino de geografia e escolas do campo: o conhecimento geográfico como um saber em conjunto. GEOUSP: espaço e tempo, América do Norte, n. 1, dez. 2011. Disponível em: <http://citrus.uspnet.usp.br/geousp/ ojs-

2.2.4/index.php/geousp/article/view/ 451/263 >. Acesso em: 14 maio 2012

OLIVEIRA, C. Ensino de geografia e ciências da comunicação: por uma geografia mundana (Geography and communication sciences: for an earthly geography). Revista Mercator, América do Norte, v. 3, n. 6, 2004.

PANIZZA, A.; FONSECA, F. Técnicas de interpretação visual de imagens. GEOUSP - Espaço e Tempo, América do Norte, 1, dez. 2011. Disponível em: $<$ http://citrus.uspnet.usp.br/geousp/ ojs-

2.2.4/index.php/geousp/article/view/ 448/260>. Acesso em: 15 maio 2012.

PEREIRA, S. A proposta curricular do estado de São Paulo e o cotidiano escolar. GEOUSP - Espaço e Tempo, América do Norte, mai. 2011. Disponível em: $<$ http://citrus.uspnet.usp.br/geousp/ ojs-

2.2.4/index.php/geousp/article/view/ 162/57>. Acesso em: 15 maio 2012. 
REGO DA ROCHA, G. Por uma geografia moderna na sala de aula: Rui Barbosa e Delgado de Carvalho e a renovação do ensino de geografia no Brasil (For a modern geography in classroom). Revista Mercator, América do Norte, v. 8, n. 15, 2009.

RICHTER, D.; MARIN, F.; DECANINI, M. Ensino de geografia, espaço e linguagem cartográfica (Geography education, language and space mapping). Revista Mercator, América do Norte, v. 9, n. 20, 2010.

REFATTI, L. V.; REGO, N. Representações de mundo, geografias adversas e manejo simbólico: aproximações entre clínica psicopedagógica e ensino de geografia. Terra Livre, Goiânia, ano 20 , v. 2, n. 23, p. 75-85, jul./dez. 2004.

SALES, M. A. Estudos em geografia: um desafio para o licenciando em pedagogia. Terra Livre, Presidente Prudente, ano 23 , v. 1 , n. 28 , p. 149-162, jan./jun. 2007.

SANTOS, M. Por uma outra globalização. Rio de Janeiro: Record, 2002.

SANTOS, R. E. Ensino de geografia e currículo: questões a partir da Lei 10.639. Terra Livre, São Paulo, ano 26, v. 1, n. 34, p. 141-160, jan./jun. 2010.

SILVA, A. M. R.; SPINELLI, J. Ensino e pesquisa: refletindo sobre a formação profissional em geografia pautada no desenvolvimento da competência investigativa. Terra Livre, v. 28, n.1, p. 163-176, 2007.

SILVA, J. L. B. ; RAMIRES, R. R. Onde se constrói a identidade formativa do geógrafo e do professor de geografia? Ou ainda, é possível fazer geografia nos cursos de geografia? Terra Livre, Dourados/MS, ano 24, v. 2, n. 31, p. 173-179, jul./dez. 2008.

SILVA, V. P. O raciocínio espacial na era das tecnologias informacionais. GEOUSP
- Espaço e Tempo, América do Norte, jun. 2011. Disponível em: <http://citrus.uspnet.usp.br/geousp/ ojs-

2.2.4/index.php/geousp/article/view/ 248>. Acesso em: 15 maio 2012.

- O raciocínio espacial na era das tecnologias informacionais. Terra Livre, Presidente Prudente, ano 23, v. 1 , n. 28, p. 67-90. jan./jun. 2007a.

- A formação do professor de geografia na era da informação. Geosul, Florianópolis, v. 22, n. 43, p 167-198, jan./jun. 2007b. Disponível em:

<http://www.periodicos.ufsc.br>. Acesso em: 18 maio 2012.

SMITH, N. Quem manda nesta fábrica de salsicha? Geosul, v. 18, n. 35, 2003. Disponível em:

<http://www.periodicos.ufsc.br>. Acesso em: 18 maio 2012.

SPOSITO, M. E. B. O local, o nacional e o global na geografia e as práticas escolares. Geosul, Florianópolis, v. 17, n. 33, p. 143-168, jan./jun. 2002 Disponível em:

<http://www.periodicos.ufsc.br>. Acesso em: 18 maio 2012.

STRAFORINI, R. A totalidade mundo nas primeiras séries do ensino fundamental: um desafio a ser enfrentado. Terra Livre, São Paulo, ano 18 , v. 1 , n. 18 , p. 95-114, jan./jun. 2002.

TEODORO, T. B. O ensino da geografia e os jovens em situação de risco social: "por uma geografia cidadã". Terra Livre, São Paulo, ano 25, v. 2, n. 33, p. 125-138, jul./dez. 2009.

TONINI, I. Imagens nos livros didáticos de geografia: seus ensinamentos, sua pedagogia... (Pictures in geography textbooks: their lessons, their pedagogy...). Revista Mercator, América do Norte, v. 2, n. 4, 2003. 